\title{
REDUÇÃO DA MAIORIDADE PENAL E MÍDIA: uma análise crítica sobre a criminalização da violência juvenil
}

\author{
Ana Clara Montenegro Fonseca ${ }^{1}$ \\ Mateus Carvalho Sá ${ }^{2}$
}

\begin{abstract}
RESUMO
O objeto do artigo centra-se na questão da redução da maioridade penal e sua relação com as produções do campo midiático que influem no discurso de criminalização da violência juvenil, propiciando, sobretudo, a construção de um direito penal meramente simbólico, a partir de produções legislativas emergentes. Parte-se de uma perspectiva incomum no tratamento do tema, porque a finalidade ora proposta distancia-se do debate localizado na diferença entre posturas dentro de movimentos ideológicos de ser contra ou a favor da redução. Nesse sentido, aproxima-se da investigação dos novos arranjos que promovem mudanças nas relações sociais, destacando os efeitos de poder midiático, tido como um quarto poder, que circula entre as pessoas e influi no aparecimento de novas verdades, como o "reduzir é solução", por exemplo, e, a partir disso, percebe-se a eficiência (ou não) que o direito penal tem em responder tais questões. Para tanto, sublinha-se o caráter teórico da pesquisa, com posição crítica e interdisciplinar, no propósito de explicar as relações entre o fenômeno (redução da maioridade) e outros contextos (direito, mídia e política). O artigo estrutura-se pela apresentação do conceito adotado no estudo de mídia como quarto poder, depois foca a discussão sobre os fatores econômicos, o sensacionalismo e a cultura do medo como instrumentos a serviço da mídia e, por último, trata do papel dessa mídia na formação de processos de criminalização da violência juvenil que repercutem na criação de projetos legislativos sobre o tema na contemporaneidade. Assim, percebe-se a existência de uma complexa engrenagem que congrega a mídia, as produções legislativas e a redução da maioridade penal, a qual o debate legalista por si só é insuficiente na apreensão de seu sentido, por isso, a abordagem transdisciplinar proposta aponta novo horizonte a fim de enriquecer a discussão.
\end{abstract}

Palavras-chave: Maioridade penal. Mídia. Poder Legislativo. Violência Juvenil. Simbolismo.

\section{INTRODUÇÃO}

\footnotetext{
1 Mestra pela UFPE- Universidade Federal de Pernambuco. Professora assistente na UFPB UNIVERSIDADE FEDERAL DA PARAÍBA. E-mail: anaclarafonseca@gmail.com.

${ }^{2}$ Graduado em Direito pela UFPB- UNIVERSIDADE FEDERAL DA PARAÍBA. Advogado. E-mail: mateuscsa7@gmail.com.
} 
Sabe-se que a temática da redução da maioridade penal promove incontáveis e calorosos debates na sociedade brasileira contemporânea. O assunto é debatido há mais de duas décadas, desde quando o marco etário de dezoito anos foi estabelecido pela ordem constitucional de 1988, além de ser pauta frequente veiculada nos noticiários. Apesar da atualidade da discussão dogmática, ou seja, dos constantes embates de movimentos ideológicos entre os favoráveis e os refratários à redução, enfoque ora aventado nesse estudo distancia-se dessa visão reducionista e legalista de análise do tema com foco meramente da norma.

Assim, a presente pesquisa centra-se precipuamente na questão da redução da maioridade penal e sua relação com as produções do campo midiático, as quais influem no discurso de criminalização da violência juvenil. Analisa-se, pois, as conexões que ocorrem entre os mecanismos a serviço da mídia (fatores que estão por trás do interesse em difundir a violência juvenil e sua criminalização) e os processos legislativos tendentes à redução da maioridade em tela. Nessa trilha, busca-se criticar a formação de um direito penal meramente simbólico, oriundo de produções legislativas emergentes, que, por seu turno, revestem-se de suposta legitimidade (clamor e apoio popular), insuflado pelo do chamado quarto poder, a mídia.

Nesse sentido, o trabalho aproxima-se da investigação dos novos arranjos que promovem mudanças nas relações sociais, destacando os efeitos de poder midiático, tido como um quarto poder, que circula entre as pessoas e influi no aparecimento de novas verdades, como o "reduzir é solução", por exemplo, e, a partir disso, percebe-se a eficiência (ou não) que o direito penal tem em responder tais questões.

Dito de forma simples, intenta-se analisar a natureza das ligações e arranjos existentes entre a mídia, o Poder Legislativo e a criação de leis penais. Dessa forma, discute-se a influência que a mídia exerce sobre o Poder Legislativo e sobre a sociedade, tornando atraentes e críveis certas medidas legislativas como meio para solucionar determinados problemas, como é o caso da violência juvenil. Além disso, com essa perspectiva, examinam-se os sujeitos que são alvo dessa exacerbada exposição midiática, no sentido destacar a seletividade do sistema na edição de leis penais.

Para tanto, sublinha-se o procedimento de pesquisa bibliográfico e o caráter teórico da pesquisa, com posição crítica e interdisciplinar, no propósito de explicar as relações entre o fenômeno (redução da maioridade) e outros contextos (direito, mídia e política). 
Nesse diapasão, o artigo estrutura-se inicialmente pela exposição de aspectos evolutivos e realça-se a importância da mídia na sociedade contemporânea. Em seguida, observa-se a dinâmica da mídia enquanto meio de informação, bem como fiscal de comportamentos sociais. Assim, chega-se ao exame das funções da mídia e seus limites, estudando, a partir disso, o que denomina mídia como Quarto Poder.

Em um segundo momento, busca-se estudar os fatores econômicos, a cultura do medo e o sensacionalismo, os quais suportes da mídia para fomentação da criminalização da violência juvenil, que repercutem na criação de projetos legislativos sobre o tema na contemporaneidade.

Para comprovar tal hipótese, debruça-se sobre as propostas de emenda à Constituição, seja da Câmara dos Deputados ou do Senado Federal, tendentes a reduzir a maioridade penal, desde a primeira em 1989 até as últimas de 2014. Nesse passo, examinam-se os conteúdos, justificativas e o contexto social e político, vivenciado no momento destas proposições. Ainda, averíguam-se as produções midiáticas em períodos anteriores e posteriores a propositura das referidas emendas, observando os enlaces entre elas.

Por último, busca-se examinar se as propostas de emenda à Constituição apresentam-se como forma de ampliação da atuação do direito penal (expansionismo penal), além de se indagar o caráter simbólico e emergencial dessas propostas. Ademais, debate-se a construção do paradigma "segurança cidadã" também como fator influente no processo que criminaliza a violência de adolescentes e jovens.

Em suma, percebe-se a existência de uma intricada engrenagem que congrega a mídia, as produções legislativas e a redução da maioridade penal, a qual o debate legalista por si só é insuficiente na apreensão de seu sentido, por isso, a abordagem transdisciplinar ora proposta aponta para um horizonte diverso a fim de enriquecer a discussão e buscar minimizar as complexidades existentes.

\section{REFERENCIAL TEÓRICO}

Como base teórica utiliza-se Pierre Bourdie, especialmente sua obra "Sobre a Televisão" e "Poder Simbólico". Pela primeira debate-se a forma como a televisão exerce seu papel de informar dentro da sociedade e como os jornalistas tratam as questões sociais e de que formas se valem na análise de tais fatos. A partir das lições de Bourdie, demonstra-se a relação íntima entre os meios de comunicações e os interesses econômicos 
de seus detentores (a rentabilidade econômica). Já as discussões atinentes ao poder simbólico das leis parte-se do referencial de que as leis exercem um poder tanto do ponto de vista abstrato, metafísico e que portanto gera efeitos somente no psicológico das pessoas, assim como simbólico com representatividade real, gerando efeitos concretos. A primeira forma de simbologia está mais ligada aos conceitos trabalhados por André Callegari, enquanto a segunda forma de analise da simbologia está mais adstrita ao que leciona Pierre Bourdie em sua obra "o Poder Simbolico".

Para confrontar tais ideias traz-se à baila outro marco teórico: André Callegari e Maiquel Wermuth. Isso porque as produções aqui utilizadas, o poder simbólico para tais é somente representativo, abstrato, não chegando ao campo da realidade. As duas formas de ver o que é simbólico podem ser observadas quando da criação de leis, que têm cunho eminentemente representativo. Esses autores abordam-se suas ideias sobre produções midiáticas e sua influência na produção legislativa, em especial na produção de leis penais. Exatamente, o que se busca discutir no presente trabalho, de modo a perceber a relação entre as propostas de emenda à Constituição, tendentes a reduzir a maioridade penal, na medida em se que apresentam enquanto expansão do direito penal simbólico.

Na discussão acerca do sensacionalismos e cultura do medo, analisa-se a obra de Barry Glassner, que examina o medo a que é induzida a sociedade norte americana, contexto que embora diverso do brasileiro se amolda de forma coerente a nossa realidade midiática. Nessa discussão sobre risco e perigos, algumas considerações de Zygmunt Bauman são estudadas, pois este observa que vivemos em sociedade em que os riscos estão intimamente ligados so simples fato de estarmos vivos, de modo que qualquer coisa grave pode vir a acontecer com as pessoas a qualquer momento. Tais discussões corroboram com o que podemos analisar como efeitos das praticas apelativas estudadas pela mídia que geram os medos dos riscos inerentes à vida.

Por último, Michael Foucault, em Vigiar e Punir acerca das classes subalternizadas, quando trata da ingenuidade em acreditar que a lei é feita para todos, quando, ao contrário, sua aplicação não se refere a todos da mesma forma; que nos tribunais não é sociedade que julga um dos membros, mas uma categoria social encarregada da ordem. Foucault realiza uma análise histórica das formas de tornar dóceis os sujeitados, aparecendo o direito enquanto forma de dominação entre classes sociais. De forma, todos esses ensinamentos servem de alicerce na crítica à redução da maioridade 
penal institucionalizada pelo quarto poder, a mídia, que em muito fomentam a criação de leis simbólicas, que trazem no seu amago intenções de forma disfarçada.

\section{RESULTADO E DISCUSSÃO}

\section{1 o papel da mídia frente à redução da maioridade penal como um quarto poder}

Os meios de comunicação são instrumentos de extrema importância nas relações que se mantem em um Estado democrático de direitos. No Brasil, no período obscuro da ditadura militar, estes meios sofreram graves violações de modo que a censura existente impedia que se mostrasse a realidade vivida. Isso dava toda a possibilidade de que a "Ditadura" perpetuasse seus descalabros, seus desrespeitos, sem que fosse importunada. Depois da Ditadura, a mídia transformou-se e passou, então, a exercer seu papel e a ter os direitos respeitados, podendo mostrar o que acontece na sociedade.

Os meios de comunicação, são espaços onde deve haver uma multiplicidade de vozes que precisam ser difundidas na análise da situação determinada, é o espaço que deve mostrar a realidade com "imparcialidade" no sentido de não transfigurar os fatos em razão de interesses individuais, franqueando aos atores a possibilidade de difundir suas opiniões e ideias. Em tese, a mídia deveria noticiar de forma mais imparcial possível, permitindo ao espectador, à população, conhecer os fatos sem influências ideológicas e políticas.

Deste modo, a mídia deixa de exercer influência somente no campo midiático e passa a exercer influência também no campo da cultura e da política. Pois quando a mídia além de noticiar, o faz de forma tendenciosa, ela toma partido e acaba por gerar resultados tendenciosos que reverberam na posição da sociedade perante a política, ou qualquer outro assunto de interesse público.

Importante deixar claro que ao falarmos de mídia ou meios de comunicação, utilizamos esses termos de forma genérica abrangendo todos os meios de comunicação e mídia possível, desde revistas e jornais, televisão e rádio, e também o meio mais atual de difusão de informações que a internet, ou seja, os meios digitais.

A mídia atua como se fosse um “Quarto Poder” da República, esta expressão passou a ser muito utilizada em alusão ao grande poderio concentrado nas mãos dos grupos midiáticos de modo que eles têm tanto poder quanto os outros três poderes legalmente constituídos, o Executivo, Legislativo e Judiciário. 
Mas é importante notar que o grande proposito e preocupação da mídia é com o interesse do público e não com o interesse público. Pois uma de suas maiores preocupações é com o retorno econômico, esse é o grande fim dos grandes conglomerados midiáticos.

Como bem sintetiza Oacir Silva Mascarenhas:

O problema é que, apesar da falta de legitimidade, a Mídia vem, de fato, exercendo poderes que exorbitam da ótica constitucional. A Mídia vem se impondo como "Quarto Poder", uma espécie de imposição, que nos parece um tanto quanto totalitária. É um poder que está além do Estado. (MASCARENHAS,2011, p.25, grifo nosso).

A mídia apresenta-se, muitas vezes, como um poder, ao lado dos Poderes Executivo, Legislativo e Judiciário, em uma sociedade democrática, em que há ampla liberdade de expressão. Nesse sentido, posiciona-se em um elevado patamar para a formação de opinião e para a busca de construção de consensos e identidades na sociedade contemporânea.

Outrossim, disso surge uma primeira problemática: a ocultação de seus paradoxos, ou seja, como poder paralelo aos demais, ela também carrega em si diversos interesses, sobretudo os de seus detentores e os dos que podem financiar a divulgação de seus conteúdos. Nesse campo, é que a função da mídia extrapola-se à ideia de informar e chega à invenção de realidade. A maioria da sociedade somente enxerga a superficialidade desse processo, assistindo acriticamente a ausência de limites, em certos casos, da atuação desse poder.

Nesse sentido, Pierre Bourdieu assevera que:

Os Jornalistas têm "óculos” especiais a partir dos quais veem certas coisas e não outras; e veem de certa maneira as coisas que veem. Eles operam uma seleção e uma construção do que é selecionado. O princípio de seleção é a busca do sensacional do espetacular. (BOURDIEU,1997, p.25).

Percebemos que a mídia não mostra tudo o que acontece, mas somente o que os seus “óculos especiais” enxergam. De modo que não sendo do ponto de vista jurídico e constitucional, um poder, a mídia acaba exercendo grande influência, em especial na formação da opinião pública, logo, como encargo ou obrigação ela deveria agir com extremo cuidado, pois deve ser compromissada diante do importante papel que ocupa na sociedade. 
No Brasil, a regulamentação dos meios de comunicação é deficiente, existem dois órgãos que compõem o sistema de regulamentação das telecomunicações o Ministério das Comunicações e a ANATEL, esta última criada pela lei geral de telecomunicação. O que nos parece claro é a inoperância e falta de efetividade desses órgãos na atuação de fiscalização, pois diuturnamente vemos situações de desrespeito, de violação a direitos fundamentais, perpetrados pelos meios de comunicação e nada é feito, nenhuma atitude é tomada, ninguém é responsabilizado. Não queremos falar em censura, pois nos coloca de volta aos tempos tenebrosos da ditadura, mas não pode a mídia continuar exercendo seu papel de forma desordenada e sem nenhum tipo de cuidado. Se ela não é um “Quarto Poder”, pelo menos oficialmente, mas ocupa o espaço de um, deve ter no mínimo responsabilidade e limitações,

Se a Mídia se arvora como um "Quarto Poder", deve ter controles e limites, pois poder sem limites é tirania. [...] Os jornalistas não devem olvidar que a liberdade de imprensa garantida na Constituição Federal (CF) não é ilimitada. (MASCARENHAS, 2011, p.32, grifo nosso).

O campo midiático não pode fazer às vezes de todos os outros poderes, de modo a legislar, julgar e executar funções estatais. Além disso, atuando em especial nos temas que mais lhe interessam, importando-se somente, com o que enxergam seus "óculos especiais".

Quando a mídia se apresenta como um poder e que tem realmente força e disposição para buscar satisfazer seus interesses, ele se torna muito perigosa. Deixa de ser somente um elemento essencial na fiscalização do estado e passa a ocupar uma posição de influência dentro da agenda política do país, nas decisões do judiciário, entre outros.

\section{2 fatores de influência no campo midiático: a pressão do campo econômico}

A mídia sofre grande influência do campo econômico, pois para existir um meio de comunicação precisa ser viável economicamente, e então os interesses econômicos prevalecem sobre qualquer outra coisa,

Pode-se pensar também nas censuras econômicas. É verdade que, em última instancia, pode-se dizer que o que se exerce sobre a televisão é a pressão econômica. Dito isto não podemos nos contentar em dizer que o que se passa na televisão é determinado pelas pessoas que a possuem, pelos anunciantes que 
pagam a publicidade, pelo Estado que dá subvenções [...]. (BOURDIEU,1997, p. 65 , grifo nosso).

No trecho acima o autor fala mais especificamente sobre a televisão, mas o que é dito se aplica também aos outros meios de comunicação. A influência econômica não é o fator único, mas ele é um fator de grande importância no entendimento da engrenagem que move a mídia. Os meios de comunicação precisam ter audiência, para que possam ter cada vez mais anunciantes e por consequência mais arrecadação financeira.

Obviamente, a influência exercida pelo campo econômico no que a mídia produz não é de forma direta, é indiretamente, pois o trabalho da mídia vai ser mostrar aquilo que lhe traga audiência, de modo que os grupos econômicos se interessem em investir em anúncios e em propagandas para o maior número de pessoas possível.

A busca por anunciantes gera entre os grupos midiáticos uma grande concorrência, gerando uma corrida desenfreada por notícias mais vendáveis, essa disputa muitas vezes não tem escrúpulos fazendo com que mais uma vez a mídia perca sua credibilidade.

No trecho abaixo Bourdieu faz uma análise interessante:

\footnotetext{
Nada tenho, evidentemente, contra a concorrência, mas observo apenas que, quando ela se exerce entre jornalistas ou jornais que estão sujeitos às mesmas restrições, às mesmas pesquisas de opinião, aos mesmos anunciantes [...] ela homogeneíza. Ninguém lê tanto jornais quanto os próprios jornalistas. (BOURDIEU, 1997, p. 110, grifo nosso).
}

Muitas vezes os jornalistas estão mais preocupados com a concorrência, de modo que a maioria dos jornais traz em suas manchetes praticamente o mesmo conteúdo que os outros, a diferença é muito pequena, cada meio de comunicação vai tentar buscar algo que ainda não foi dito, para se diferenciar dos demais. Essa homogeneização é também negativa no sentido de que uma parcela mínima de informações é repassada para sociedade, outras tantas informações deixam de ser repassadas. "Há, hoje, uma 'mentalidade-índice-de-audiência' nas salas de redação, nas editoras etc. Por toda parte, pensa-se em termos comerciais”. (BOURDIEU,1997, p.115).

Além do que, a forma que a mídia analisa cada tema vai influenciar preponderantemente na forma que a sociedade vai enxerga-lo. Quem possui a informação possui o poder de fazer com ela o que lhe interessa, de modo que leva a opinião pública para o lado que melhor lhe satisfaz. 
Abaixo, uma constatação:

Desta forma, a posse do poder comunicador pode se tornar instrumento de manipulação, porque permite dominar a partir da interioridade da consciência do outro, criando adesões que interiorizam a verdade e a evidencia do mundo dominador, condenando e estigmatizando a pratica e verdade do oprimido como pratica antisocial. (OLIVEIRA JUNIOR,2012, p.24, grifo nosso).

$\mathrm{Na}$ transcrição acima, fica ainda mais claro o poder de manipulação que está nas mãos dos meios de comunicação, as informações apresentadas podem estar guardando muitos outros interesses. E politicamente podem ser instrumentos de extrema importância, em inúmeros momentos, seja eleitoral ou posteriormente quando já no governo, para passar imagens positivas de sua gestão, servindo, portanto, a mídia de instrumento de manipulação social.

Assim como nos atos cometidos por adolescentes, ponto central de discussão neste trabalho, que são muito utilizados pela mídia, levando, a forma com que são apresentados tais fatos, a criar na sociedade uma sensação de grande quantidade e de especial crueldade no cometimento destes atos.

\section{3 instrumentos a serviço da mídia: sensacionalismo e cultura do medo}

Os meios de comunicação ao noticiarem um determinado fato não se preocupam de forma primária somente em mostrar os fatos exatamente como eles ocorreram, isto não é suficiente para chamar a atenção do destinatário. Mais que qualquer outra coisa é preciso fazer com o que leitor se interesse pelo que está sendo passado, de modo que aquela experiência traga nas pessoas sensações diferenciadas levando-o a querer acessar cada vez mais esse tipo de informação. Um instrumento utilizado para alcançar tal interesse, é o fenômeno chamado Sensacionalismo, que busca despertar sentimentos nas pessoas de modo que elas fiquem ligadas emocionalmente aquele tipo de notícia, a sensação que as pessoas é pertencer aqueles fatos de ser parte daquilo ou de mesmo de poder se tornar parte daquilo ou seja de enxergar clara possibilidade de que aqueles fatos narrados possam acontecer também com eles.

O Sensacionalismo é uma forma alternativa de passar as informações, é uma possibilidade que surpreende e é capaz de chocar o público. Estratégia que é utilizada pelos meios de comunicação, utilizando-se de uma linguagem vulgar e muito facilmente compreendida pelo espectador, não é necessário raciocinar. Não há nenhum cuidado com 
o que se fala, a intenção é chocar, envolvendo emocionalmente o público. O que traz o espectador para dentro da notícia, ele a integra. Este tipo de atuação da mídia é de um mundo abstrato, um mundo de imaginação, que deixa o espectador sem saber discernir o que real do que é artifício, criado pelo sensacionalismo.

O sensacionalismo utiliza-se das manchetes, que despertam, a atenção mas não dizem tudo, geram curiosidade, vontade de saber o que aconteceu, e a notícia aparece carregada de suspense, que gera nas pessoas grande surpresa positiva ou negativamente. Além disso, as notícias são passadas muitas vezes de forma deturpada, palavras não ditas são acrescentadas, outras são retiradas do texto, tudo com intenção de deixar aquela notícia mais atraente, mais chamativa. A tentativa é de tornar aquele fato como algo corriqueiro, comum, que qualquer pessoa possa facilmente se ver descrito naquela situação.

Pierre Bourdieu elenca alguns fatores, que segundo ele influenciam no sensacionalismo,

\footnotetext{
Contribuem para o sensacionalismo pelo menos quatro fatores: a) a definição de temas (pautas), b) a intensidade emocional adotada, c) a exploração artificialmente prolongada de fatos escandalosos e, d) a natureza das emoções do público que se pretende manipular. Uma coisa é manipular a compaixão perante o próximo em prol de causas filantrópicas, por exemplo, outra, muitos diferente, é manipular o medo, a revolta ou a ira, quando não a morbidez, como é comum acontecer em reportagens policiais." (BOURDIEU, 1997, p.52).
}

Segundo o primeiro fator a televisão e também os outros meios de comunicação buscam temas que tragam maior visibilidade, curiosidade das pessoas destinatárias, além do que, de acordo com o segundo critério, precisam ter apelo emocional, devem mexer psicologicamente com as pessoas. Diante do outro fator, é preciso que aquele tema tenha capacidade de ser protelado no tempo, que novas descobertas sejam feitas ao longo das reportagens, como se esta fosse inclusive uma investigação, que cada fato novo descoberto possa atrair a atenção das pessoas, assim como no enredo de uma novela, e, de tal modo, como assevera o último fator, a forma como as emoções das pessoas poderão ser manipuladas, a depender da notícia que esteja sendo apresentada, seja sentimento de vingança, raiva, admiração, entre outros.

O crime é sem dúvida o tema mais utilizado pela mídia para tornar espetáculo. Temos vários exemplos de crimes que por sua crueldade e apelo midiático acabam virando verdadeiros circos, onde a mídia faz a análise de todos os fatores, mas não de forma imparcial, ela assume a posição que seja vendável. A sensação de injustiça que é 
colocada nas pessoas gera grande comoção, porque a mídia faz também julgamentos antecipados e condena antes mesmo de o Judiciário se pronunciar. A violência e, por consequências as notícias e reportagens, são objetos que utilizados pela mídia, de forma a atrair mais público, gerando, portanto lucro. Tudo isso, fruto da pressão que campo econômico, como dito em tópico anterior, exerce sobre o campo midiático.

\begin{abstract}
Os meios de comunicação acabam apresentando uma realidade criminal distorcida. Ao invés de se limitar a reconhecer e apresentar os problemas e os fatos, a Mídia constrói uma imagem virtual que não condiz com a realidade. $\mathrm{O}$ resultado disso é a construção do imaginário popular. A sensação de pânico e de terror fica estabelecida da forma mais sensacionalista possível. (MASCARENHAS, 2011, p.6, grifo nosso).
\end{abstract}

Acredita-se que a desmistificando-se as reais funções da mídia ela perde sua credibilidade, pois não utiliza sua "liberdade de imprensa" da forma como deveria. Enfraquece sua relação com aquilo que deveria ser princípio basilar de sua atuação: a imparcialidade, pois faz analises tendenciosas, buscando sempre satisfazer os seus interesses, que está intimamente ligado a fatores políticos, econômicos entre outros. Quando falamos em imparcialidade, é importante que se destaque não acreditamos que ela seja passível de ser alcançada completamente, o que queremos dizer é que os meios de comunicação devem se furtar de ter interesses que fujam à sua responsabilidade que é mostrar os fatos, sem ser tendenciosos e etc.

A sociedade moderna tem, diante de suas peculiaridades, sido estudada e analisada por muitos estudiosos. Fala-se hoje em sociedade de risco neste ponto por Ulrich Beck, seria um efeito dos processos de modernização da sociedade, que se da pósrevolução industrial, no qual a sociedade passa viver sobre constates riscos, ante a impossibilidade de saber o que pode acontecer em momentos futuros, ante a gama de possibilidades existentes na sociedade atual. (CALLEGARI; WERMUTH, 2010, p.13).

Wemuth e Callegari, ao discutiram tal conceito, fazem uma análise e sintetizam o mesmo:

O conceito de sociedade de risco, portanto, designa um estágio da modernidade em que começam a tomar corpo as ameaças produzidas até então no caminho da sociedade industrial, impondo-se a necessidade de considerar a questão da autolimitação do desenvolvimento que desencadeou essa sociedade. A potenciação dos riscos da modernização caracteriza, assim, a atual sociedade de riscos que está marcada por ameaças e debilidades que projetam um futuro incerto. (CALLEGARI; WERMUTH, 2010, p.14). 
Os riscos da sociedade moderna são situações que todas as pessoas desde muito jovens trazem dentro de si. A grande probabilidade de que várias coisas possam acontecer gera todo esse risco, de modo que a qualquer momento, por exemplo, uma grande catástrofe ambiental possa acontecer, um ataque terrorista possa acontecer e em um instante matar milhares de pessoas e de que pode-se ser vítima de um crime bárbaro, cometido por psicopata ou algo do tipo.

Dentro dessa realidade, fala-se hoje em uma "cultura do medo", que é um dos instrumentos utilizados pelos meios de comunicação na busca pela audiência e também pela manutenção da mesma. Tal situação é perceptível em especial quando se trata de crimes, onde a mídia se utiliza daquele caso para despertar nas pessoas a sensação do medo e da insegurança, ainda que elas não sejam verdadeiras.

Segundo Barry Glassner,

\footnotetext{
Entre todos os medos contemporâneos aos quais se poderiam citar, o medo do crime é um dos mais instigantes. O medo do crime é um sentimento que povoa a mente humana desde a infância e as histórias infantis souberam, com nenhum ou meio de comunicação como lidar com esse sentimento. (GLASSNER, 2003, p.74, grifo nosso).
}

São casos de crimes bárbaros que não acontecem com tanta frequência, mas o longo período que passam sob os holofotes geram a sensação de que se está diante de algo corriqueiro. Semelhante ao que acontece quando, coincidentemente, casos de crimes parecidos, seja pelo uso de um tipo de arma especifica, seja pela forma como agem os criminosos, cria-se "ondas de crime", estabelece-se vínculos entre aqueles fatos de modo que eles parecem algo até orquestrado, causado de forma pensada, quando na verdade é somente uma coincidência, essa é uma arma muito utilizada pelos meios de comunicação, que acaba gerando nas pessoas a vontade de estar informada sobre aqueles fatos e ainda gera sensação de insegurança e o medo, diante daquelas situações que faz-se parecer cotidiana.

A postura da mídia é irresponsável, "por uma estranha alquimia, estatísticas irrisórias são transformadas em cifras atemorizantes, que crescem de acordo com o aumento dos níveis de audiência" (GLASSNER, 2003, p. 23), utiliza dados a seu favor, os observa a partir de sua lógica mercadológica, passando o que suas lentes querem mostrar, ou melhor o que lhes parece mais vendável e atrativo. É raro ainda a utilização de dados, que a depender do público alvo do veículo de comunicação, eles são 
completamente desnecessários, o público que observa dados é geralmente mais qualificado.

Com isso, os pseudoperigos que jorram dia a dia das manchetes televisivas e da mídia impressa representam novas oportunidades de evitar problemas que não queremos enfrentar[...], assim como aqueles que já cansamos de confrontar [...] banalizar preocupações legítimas enquanto engrandecem aquelas questionáveis. (GLASSNER, 2003, p.55 e 56).

A mídia cria perigos que estão sempre prestes a acontecer com qualquer pessoa, e que são problemas novos e, talvez, nem tão corriqueiros, quanto se faz com que ele pareça. Assim a mídia acaba por tirar o foco das coisas importantes que estão ligadas aos fatos, ou deixa de mostrar notícias que seriam de muito maior interesse da sociedade. Temas de relevância social são deixados de lado, e quando são mostrados apresentam o viés que seja mais vendável e na maioria dos casos não discute de forma coerente o tema em questão.

A cultura do medo, aqui discutida é uma importante ferramenta no processo que acontece hoje no Brasil, que gera um temor cada vez maior de crimes cometidos por adolescentes. Quando ocorre algum caso de crimes graves cometidos por adolescentes os meio de comunicação utilizam-se de todos os artifícios possíveis para gerar comoção e medo desse tipo de acontecimento. Toda essa conjuntura leva a discussões emocionais que deixam a razão de lado quando o tema é a redução da maioridade penal, afinal isso é obvio, que não se sentiria apavorado, com todos os meios de comunicação falando por semanas dos detalhes de um ato de violência cometido por adolescentes. Além das semanas posteriores aos crimes os meios de comunicação também relembram os aniversários desses fatos, como se fossem datas comemorativas dos crimes, a intenção é fazer com que as pessoas não esqueçam e fiquem tão emocionalmente ligadas aquilo que não conseguem para de consumir esse tipo de publicação.

Nesse sentido, se perverte e passa a exercer uma função de quarto poder, que passa a influenciar de forma sensível toda a sociedade e constitui-se enquanto um dos maiores formadores de opinião na nossa atual sociedade. Influência também os poderes legalmente constituídos, passando por exemplo a exercer pressões sobre as políticas criminais a serem adotadas pelo estado. Para isso ela se utiliza de alguns subterfúgios como o sensacionalismo e a cultura do medo, que reforçam a ideia de uma sociedade de risco, ou vice e versa, pois a sociedade de risco também atua de forma idêntica. 


\section{ANÁlise CRÍtica SOBRE AS PROPOSTAS DE EMENDA CONSTITUCIONAIS (PEC'S) TENDENTES À REDUÇÃO}

A partir de agora faremos uma análise das PECs relacionadas à redução da maioridade penal, que antecederam o ano de 2015. Serão analisadas concomitantemente as notícias midiáticas que foram veiculadas em períodos anteriores à proposição das PECs, em especial da Folha de São Paulo, para ao final verificarmos ou não o alvo de estudo, que é a influência da mídia no surgimento da PEC.

Desde promulgação da Constituição da República Federativa do Brasil(CRFB), no ano de 1989 até o ano de 2014, 52 propostas de Emenda à Constituição Federal, cujo conteúdo alterava de alguma forma o artigo 228 da CRFB, foram apresentadas, sendo 9 deles no Senado Federal e 43 na Câmara do Deputados. As primeiras PECs foram apresentadas na Câmara dos Deputados, somente no ano de 1999 o Senado Federal apresentou sua primeira proposta sobre o tema.

A PEC no 14/89 da câmara dos deputados foi a primeira proposta a ser apresentada e propunha a redução da maioridade penal para dezesseis anos. No caso desta PEC, não foram encontrados relatos anteriores sobre o tema, pois ele ainda era pouco discutido, mas logo passaria a ser um dos mais explorados. Posteriormente no ano de 1991, uma reportagem do jornal O Globo demonstra qual seria a tônica da discussão sobre a redução, tem como título: "Para os jovens, a lei da impunidade" (DUARTE, O Globo, 1991, p.21).

No ano de 1993 uma nova proposta foi apresentada, a PEC no 171/1993, propunha a redução da maioridade penal para dezesseis anos, mas com critérios de pena diferenciados estabelecidos por lei ordinária. Traz uma justificativa mais elaborada, com argumentos mais robustos, muitos deles até hoje utilizados. Inicialmente, critica o critério biológico utilizado na determinação da maioridade penal, alegando que o jovem daquela época já era capaz de discernir sobre natureza dos atos que praticava, pois o mundo em que viviam já lhes dava essa capacidade, diferentemente dos jovens de tempos mais antigos.

De forma sucinta, mas já bem perceptível os casos de atos cometidos por adolescentes noticiados pela mídia já se apresentam como justificativa para uma redução da maioridade penal, "o noticiário da imprensa diariamente publica que a maioria dos crimes de assalto, de roubo, de estupro, de assassinato e de latrocínio. São praticados por menores de dezoito anos, quase sempre, aliciados por adultos.” (PEC n 171/1993, p.2). 
A partir da PEC 171/1993, passaram a tramitar conjuntamente a ela todas as proposições relacionadas à temática da redução, então as PECs anteriores foram apensadas a citada proposta, assim como as que vieram posteriormente.

No ano seguinte mais três novos projetos foram apresentados, foram as PECs 301, 386 e 426. A primeira, apresentada, traz a mesma mudança anteriormente defendida, reduzindo a maioridade para dezesseis anos e ficando sujeitos às normas da legislação especial. Em sua justificativa, similar as anteriormente apresentadas, diz que os jovens que levam uma vida regrada não sofrerão com esta mudança. No mesmo sentido a PEC 386 que traz texto um pouco diferenciado, já que torna imputáveis somente os maiores de dezesseis anos cometedores de crimes contra a pessoa, patrimônio e hediondos. É importante perceber a presença de mais um trecho voltado para o que apresenta a mídia sobre o tema:

Com isto, a imprensa diária em todo o País noticia a multiplicação das ocorrências delitivas, que vão desde os simples furtos à prática de violência extrema contra pessoas e bens, ao comércio de drogas, nos quais se envolvem adolescentes, revelando na maioria das vezes, a despeito da pouca idade, enorme tendência criminal e predisposição para ações mais audaciosas e desafiadoras da Polícia, da Justiça e da sociedade. (PEC 386/96, p.2).

Ainda no ano de 1996, outro projeto é apresentado, percebe-se uma possível influência do clamor social na proposta, já que pouco tempo antes um caso de ato cometido por adolescente foi noticiado. Pode-se dizer que tal proposta tem por intenção satisfazer uma necessidade momentânea e, até mesmo, servir como medida populista e mote em campanhas eleitorais. Observa-se uma discussão rasa e precipitada sobre o tema, como se percebe na justificativa do projeto:

Em 23 de janeiro do corrente ano, na cidade de Goiânia ocorreu um homicídio praticado por dois jovens um de quinze anos outro de dezessete. O crime chocou o País, não pelo fato do homicídio em si, uma vez que é tão rotineiro em nosso pobre Brasil, pela indiferença dos homicidas que, após a prática, foram passear com três garotas no carro da vítima. (PEC 426/1996, p.1).

Percebe-se que a própria parlamentar, no texto da PEC, se vale de uma situação casuística para fomentar a punibilidade pelo direito penal aos adolescentes, o que é extremamente temerário, pois não satisfaz pressupostos materiais mínimos para criação do direito penal.

Em 1998, nenhuma proposta de Emenda foi apresentada, em compensação, ano seguinte, 1999, ao todo nove propostas foram apresentadas, duas delas, as primeiras 
a serem apresentadas sobre o tema no Senado Federal. As PECs da Câmara dos Deputados foram: 68, 133,150, 167,169,301,633. Já as do senado foram as PECs 18 e 20. A grande quantidade de propostas de Emenda não foi por acaso, desde o final do ano anterior, a hoje extinta FEBEM passava por uma grave crise. No dia 24 de agosto a Folha de São Paulo noticiava, ainda de forma tímida, a ocorrência de um motim, no qual 50 adolescentes fugiram. A partir daí começava uma séria de episódios que marcaram as discussões acerca da redução e demonstravam a falência de um sistema de internação que não ressocialização os adolescentes infratores, ao contrário foram narrados episódios de graves violações a garantias e direitos humanos.

Em razão disso, ocorreu uma grande movimentação de vários de setores da sociedade no sentido do fechamento das FEBEM. Em 26 de outubro de 1999 a manchete da capa da Folha de São Paulo dizia: "Maior rebelião mata 4 na Febem" (FARIAS FILHO, FOLHA, 1999, p.10). O jornal noticiava a maior rebelião ocorrida, segundo a folha no ano de 1999, 2.252 adolescentes fugiram das casas de internação, era muito grave o problema. As Torturas sofridas pelos adolescentes foram denunciadas por familiares o que gerou grande repercussão. Os episódios ficaram conhecidos como "A guerra dos meninos". (FOLHA, 1999, p.5).

Destaque-se, mais uma vez, a forma como o tema é tratado no cenário das PEC's. Em nenhum dos projetos se fala na ineficiência e no estado de calamidade vivido pelas FEBEM naquele momento, fala-se somente em reduzir, por já terem capacidade os adolescentes de entender a ilicitude de seus atos. Percebe-se, mais uma vez, a influência da mídia nesses momentos. No primeiro projeto apresentado naquele ano, cita-se mais uma vez os veículos de comunicação:

Todos os dias os veículos de comunicação trazem estampadas em suas páginas policiais notícias de crimes perpetrados por menores de 16 a 18 anos. E isto por quê? Porque são cientes de sua impunidade, em face de uma legislação penal protecionista e paternal. (PEC 68/1999, p.2).

No ano 2000, os problemas nas FEBEM continuaram, mas apenas um projeto de emenda foi apresentado, a PEC n²60/2000, propondo a redução para dezessete anos de idade. Entre 2001 e 2002 mais quatro PECs foram apresentadas, sendo três na câmara dos deputados, 321,377,521, e uma no senado, PEC 26. Todas com propondo a redução da maioridade penal, sendo através da redução da idade propriamente dita ou através de novos critérios que definissem a imputabilidade. Em suas justificativas quase todas 
utilizam dos mesmos argumentos, de que os jovens de hoje já têm capacidade de discernimento, para saber o que é certo e o que é errado.

Nos dois anos seguintes uma grande quantidade de propostas foi apresentada logo após um crime bárbaro cometido no interior de São Paulo com a participação de um adolescente o que gerou em novembro de 2003, mais uma vez grandes discussões sobre o tema. Neste caso, Dois jovens estudantes de um tradicional colégio de São Paulo viajaram sem comunicar a seus pais, para uma a cidade chamada Embu-Guaçu, onde acampariam. Foram brutalmente assassinados por um grupo de quatro homens, dentre eles estava um adolescente conhecido por "Champinha". Foram mais seis novos projetos apresentados, sendo dois no Senado e quatro na Câmara dos Deputados.

A primeira delas, a proposta 242/2004, trazia a alteração da maioridade penal para os catorze anos de idade, já no início de sua justificativa, argumenta, "Não só em razão dos recentes acontecimentos, ligados ao bárbaro homicídio do casal de jovens Liana Friedenbach e Felipe Silva Caffé, mas em virtude da constante escalada da violência em nosso País[...]"(PEC 242/2004, p.1), e continua já no final de sua explanação "pois não podemos permanecer inertes até que um novo crime, perpetrado por um "menor", choque a já sofrida Nação brasileira." (PEC 242/2004, p. 2).

A forma como se discute o tema nesta justificativa, deixa claro que o clima de indignação e comoção diante de um crime tão bárbaro, fazendo com que apareçam proposições como esta.

No mesmo mês da apresentação deste projeto, outro foi apresentado no senado, PEC 9/2004, acrescentando um parágrafo único ao artigo 228, que passaria a serem penalmente responsáveis adolescentes que cometessem crimes hediondos e que apresentassem capacidade de entender o caráter ilícito do fato (PEC 09/2004, p.1), exatamente como ocorrera no caso do crime de grande repercussão citado.

Ao longo do ano de 2004 os outros projetos foram apresentados, na Câmara dos Deputados as PECs 272, 302, 345 e no Senado a PEC 90. Chama atenção, que em todos os projetos, como já dito anteriormente, as justificativas são muito parecidas, todas elas fazem referência a crimes bárbaros cometidos por adolescentes. Ainda na PEC 90/2004 do Senado faz-se, mais uma vez, citação expressa do crime cometido por "Champinha".

Em um período de quase dois anos, entre 2005 e o início de 2007, nenhum projeto foi apresentado, até o dia 7 de fevereiro de 2007. Um episódio trágico, ocorrido nesta data, ficou conhecido como "caso João Hélio". O carro da mãe do menino João 
Hélio foi roubado, ele ficou preso ao cinto de segurança e foi arrastado até a morte (FOLHA, 2007). Pela forma como crime aconteceu e ainda por ter sido cometido contra uma criança o crime gerou grande comoção, além disso, descobriu-se posteriormente com as investigações, que um adolescente teve participação no crime.

As novas proposições foram apresentados na Câmara dos Deputados, foram os seguintes: 48,73,85,87,125. Entre reduzir propriamente a maioridade penal e estabelecer crimes em que a inimputabilidade penal pode ser excluída. O que chama atenção agora nos projetos é a mudança de argumentos, agora o que se utiliza como justificativa é a grande utilização de adolescentes pelos adultos, para o cometimento de crime, como se pode perceber nos trechos a seguir:

\begin{abstract}
Além de adequar a legislação ao momento atual, a iniciativa será mais uma contribuição do Parlamento para o combate ao crime organizado, cujas quadrilhas recrutam, com habitualidade crescente, jovens entre 16 e 18 anos para suas ações criminosas. $\mathrm{O}$ caso do garoto João Hélio, arrastado brutalmente pelos subúrbios do Rio de Janeiro, é apenas mais um exemplo do envolvimento de menores em atividades delituosas. (PEC 85/2007, p. 3).
\end{abstract}

Os crimes de grande repercussão ocorridos tempos antes, ainda são citados, e outra vez a necessidade de resposta de forma imediata. Como no caso do menino João Hélio a participação do adolescente foi de forma menos ativa, sendo utilizado pelos seus comparsas mais velhos na ação criminosa, a necessidade agora era de que a justificativa, fosse no sentido de que se busque coibir a utilização de adolescentes pelos adultos, no cometimento de crimes.

A PEC 90/2009, é um ótimo exemplo de como a mídia pode ser de argumento para as proposições apresentadas pelo legislativo, escreve em sua proposição:

\footnotetext{
A mídia televisiva e escrita vincula constantemente casos de violência e ofensa ao ser humano praticados, cada vez mais, por adolescentes menores de dezoito anos, aptos para praticar o ilícito penal com violência ou grave ameaça à integridade da pessoa, e, no entanto, penalmente inimputáveis pela legislação brasileira. (PEC 399/2009, p. 3).
}

Usa como base para justificar o seu projeto o que é colocado pelas mídias e ainda como se não bastasse, utiliza toda sua página de número 5 para transcrever trechos de jornais e revistas que falam sobre crimes cometidos por adolescentes.

Já no Senado Federal no ano de 2011 foram duas propostas apresentadas 74 e 83. Importante destacar a primeira delas, que propõe a redução da maioridade penal para crimes de homicídio doloso e latrocínio, nos quais a partir do 15 anos os adolescentes 
poderiam ser penalmente responsáveis. Além disso, a justificativa traz inúmeros dados, dentre eles podemos citar por exemplo que do universo de adolescentes brasileiros, apenas 2\% (PEC 74/2011, p.3.) cumprem hoje medidas sócio educativas, destes 50\% estão no estado de São Paulo, um número claramente muito baixo, levando em consideração ainda que a outra metade de adolescentes que cumprem medida estão espalhados por todo o país, é um número ínfimo. Ademais, 10\% (PEC 74/2011, p.4.) dos crimes cometidos no Brasil são por adolescentes, e dos crimes de homicídio cometidos, 1,3\% (PEC 74/2011, p.4.) são cometidos por adolescentes.

São números muito baixos, diante do universo de crimes cometidos no Brasil, não é um argumento valido para medida que reduza a maioridade, os dados apresentados pelo deputado ao invés de embasarem seus argumentos eles o contradizem, pois o número de adolescentes em conflito com a lei é ínfimo. Ainda prossegue na justificativa, "Observa-se, entretanto, no Brasil um pavor social em torno da crescente criminalidade praticada por menores inimputáveis" (PEC 74/2011, p.4.).

No ano seguinte, um projeto no senado, PEC 33/2012, na Câmara dos Deputados mais dois, PECs 223 e 228. Em comum entre elas, mais uma vez, a lembrança de casos de grande comoção e de muita violência, para embasar suas justificativas, os casos já citados aqui e outros casos que geraram comoção de forma mais localizada em regiões do país.

Porém, é possível notar um cuidado maior com a temática na PEC 33/2012, pois traz de forma comedida o tema. Sua proposta é de trazer ao Ministério Público a responsabilidade em casos específicos, poder oferecer incidente que trataria o adolescente como imputável. A proposta é mais cautelosa, pois tem o cuidado de discutir a questão em alguns de seus aspectos mais importantes, ciente do perigo de legislar movido por grandes comoções, causadas por crimes bárbaros com participação de adolescentes.

Recentemente, no ano de 2013, mais uma grande quantidade de PEC's foi apresentada, e como já pudemos perceber em outros momentos da história da redução no país, um caso emblemático alavancou os novos projetos. Quatro propostas apresentadas na câmara do deputados e uma deles no senado federal. No dia 10 de abril, o jovem Victor Hugo Deppmann foi morto por um adolescente, em uma tentativa de assalto Victor foi atingido por um tiro na cabeça e morreu. No caso o adolescente que cometeu o crime estava prestes a completar 18 anos, neste caso devendo o mesmo sofrer medida socioeducativa até no máximo completar 21 anos, não sofrendo nenhum tipo de pena do Código Penal. 
As PECs da Câmara de número 272, 279, 332, 349, e a do Senado foi a PEC 21. Todas foram propostas após a morte de Victor, interessante notar que as novas PEC's mudam seu foco com relação à redução. Ao invés da redução da maioridade penal, as propostas buscam punir os adolescentes depois que eles completem 18 anos, ou seja, se o adolescente completa a maioridade enquanto cumpre medida socioeducativa, passa a ser punido pelo Código Penal. Vejamos como ficaria o artigo 228 da Constituição Federal, na proposta da PEC 332/2013 com inserção de um parágrafo único:

Parágrafo Único - Ao completar dezoito anos, o infrator terá decretada a extinção da medida socioeducativa a que foi submetido, mas, nos termos da legislação penal, continuará a responder pelo crime cometido, cuja pena será cumprida em unidade prisional construída exclusivamente para abrigar internos oriundos de estabelecimento educacional. (PEC 332/2013, p.1)

Coincidentemente, no caso que vitimou Victor, como dito anteriormente, o adolescente que o matou estava a poucos dias de completar 18 anos, sendo portanto, as mudanças legislativas se adequando perfeitamente a casos que acontecem imediatamente antes.

Por fim, os últimos projetos de Emenda à Constituição tendentes a reduzir a maioridade penal, foram apresentados na Câmara dos Deputados, no passado. São as PECs 382 e 438, que não trazem nada de novo para o cenário da discussão da redução da maioridade penal.

Na Câmara dos Deputados os projetos de emenda que ainda tramitam, estão apensadas a PEC n ${ }^{\circ} 171 / 1993$, em tramitação conjunta. No senado as PECs tramitam em conjuntos com PEC n ${ }^{0}$ 20/1999. Recentemente no mês de março de 2015, a Comissão de Constituição e Justiça opinou pela admissibilidade da PEC n ${ }^{\circ} 171 / 1993$, entendendo não ser o artigo 228 cláusulas pétrea e, portanto sendo passível de alteração.

\subsection{RELAÇÃO ENTRE O PAPEL MIDIÁTICO E OS PROJETOS DE EMENDA}

Como visto no tópico anterior, há uma intrínseca relação entre as propostas de Emenda à Constituição que buscam de alguma forma reduzir a maioridade penal e os atos cometidos por adolescentes ou que têm sua participação veiculada nas mídias. Como se percebeu a cada novo caso de grande repercussão uma grande quantidade de projetos apareciam de modo a satisfazer aquela necessidade momentânea. 
O guia criado pela secretaria de direitos humanos da presidência da república, sobre adolescentes em conflito com a lei traz uma importante constatação, vejamos:

A imprensa brasileira tem sido pautada pela comoção. O monitoramento de 54 jornais diários realizados pela ANDI ilustra o fenômeno: o número de matérias publicadas sobre maioridade penal saltou de uma média de 370 por ano para 3970 em 2007, ano da morte de João Hélio. Desse total, 1334 textos foram publicados em fevereiro, quando o crime aconteceu. (SECRETARIA DE DIREITOS HUMANOS, 2012, p.33).

Logicamente um caso de grande comoção como os ocorridos deve realmente gerar um aumento de matérias, mas multiplicar a quantidade de reportagens em dez vezes demonstra que o tema é muito rentável e que o seu aumento extraordinário não é à toa. É possível ter a mesma percepção quando pesquisamos no acervo digital da Folha de São Paulo pelo termo "maioridade penal", no ano de 2002, ano anterior ao ato cometido pelo adolescente "Champinha", apenas 14 ocorrências são encontradas, não por acaso, no ano do acontecimento, 2003, o número salta para 81 ocorrências, e no ano posterior o número volta a cair para 21 ocorrências. No ano que antecedeu o crime cometido contra o menino João Hélio, 2006, a pesquisa encontra 26 ocorrências, em 2007, ano que o crime foi cometido, o número sobe para 102 páginas que citam “maioridade penal”, no ano seguinte apenas 8 são encontrados. Em 2013, ano em que ocorreu o assassinato do jovem Victor Hugo Deppman, 71 páginas são encontradas, no anterior apenas 17 ocorrências. Resultados que corroboram com os dados anteriores.

A mídia ocupa um papel de extrema importância nos dias de hoje e não está vinculada somente a trazer a informação. É preciso ser também algo lucrativo e para que seja lucrativo é preciso ter grande visibilidade, é preciso ter autos índices de audiência. Como bem assevera Paulo Oliveira Junior,

[...] o objetivo principal dos meios de comunicação (agora com fim predominantemente econômico) deixou de ser a transmissão da informação, e passou a ser captação e manutenção da atenção do público, já que alcançando elevados índices de audiência fica mais fácil vender esta probabilidade de atenção de potenciais consumidores aos anunciantes. (OLIVEIRA JUNIOR, 2012, p.21)

É extremamente perigoso trazer informações quando a principal intenção não é mais informar, é trazer uma informação que deixe nas pessoas alguma sensação forte que não os deixe se desligar daquilo, e por vezes não os deixe pensar. Transforma-se em instrumento de dominação. Parece-nos ser muito rentável a discussão da redução da 
maioridade penal, em especial quando algum evento envolvendo adolescente surge, como ficou comprovado nos dados anteriormente apresentados.

O que dizem André Callegari e Maiquel Wermuth se adequa perfeitamente ao que acontece com os casos de atos de violência de grande comoção causados por adolescentes:

[...] falseamento de dados da realidade social, gerando enorme alarde ao vender o "crime" como rentável produto, respondendo as expectativas da audiência ao transformar casos absolutamente sui generis em paradigmas, aumentando assim, o catalogo dos medos e, consequentemente e de forma simplista como convém o discurso vendável, o clamor popular pelo recrudescimento da intervenção punitiva. (CALLEGARI; WERMUTH, 2010, p.46, grifo nosso).

Tal trecho resume a forma como mídia utiliza-se dos casos paradigmas em que há participação de adolescentes. A quantidade atos cometidos por adolescente é baixa perante os níveis de violência do nosso país, mas mesmo assim os meios de comunicação preferem fazer um grande alarde em torno deles, são muito lucrativos e geraram mais comoção e por consequência mais audiência, mais público.

Os meios de comunicação utilizam-se de vários instrumentos é um dos mais importantes é o "medo", que é introduzido nas pessoas através de uma falsa sensação de insegurança. Como asseveram André Callegari e Suelen Webber,

\footnotetext{
Nesse contexto de insegurança, risco e complexidade, nada seria mais "lucrativo" do que lidar com o medo, uma vez que essa seria a mercadoria à disposição nesse século. Para ganhar esse mercado, a imagem de acontecimentos sociais passa a ser manipulada em busca de maior audiência. (CALLEGARI; WEBBER, 2013, p.46, grifo nosso).
}

A sensação que os meios de comunicação deixam nas pessoas é de que somente o endurecimento das leis, é que vai acabar com o medo que elas têm. No caso dos adolescentes em conflito com a lei, somente a redução é que seria a solução para toda a problemática. (CALLEGARI; WEBBER, 2013, p.61.)

Tudo isso passa a ter uma influência dentro do poder legislativo que como pudemos perceber no tópico anterior, pauta sua atuação de modo a satisfazer aquela necessidade momentânea gerada pela sociedade inflamada pela mídia. 
interferência do Direito Penal. (CALLEGARI; WERMUTH, 2013, p.64, grifo nosso).

Na passagem acima, André Callegari e Maiquel Wermuth, relacionam de forma precisa, esse fenômeno que causa medo nas pessoas e termina por influenciar a atividade legislativa, não é algo que acontece por acaso, é um ciclo quase que natural, realidade dos dias atuais. Tudo isso, reflete a realidade vivida na temática da redução é comprovada pela profunda pesquisa feita nas PECs da redução e o momento no qual elas estão inseridas. Portanto, em resumo, um ato bárbaro é amplamente noticiado pela mídia, o que gera na população uma sensação de que adolescentes são os maiores criminosos do nosso país, e que todos os crimes por eles cometidos são bárbaros e de crueldade incalculável. A sensação que a população vai ter é medo, insegurança, o que só seria resolvido pelo enrijecimento das leis, no caso dos adolescentes, com medida drástica da redução da maioridade penal.

Essas medidas rápidas têm por intenção precípua, não a resolução dos problemas vividos, já que mesmo que a vontade fosse de resolver o problema, essas medidas seriam completamente sem efeitos. Zygmunt Bauman traz, ao dizer que o aumento das penas e criação de leis mais severas, passa à sociedade a sensação de que aquele governo é melhor, e o tornam mais popular, pois estes fazem algo pela população de forma geral, não pensando exclusivamente na própria segurança, é como se a lei fosse algo concreto que gera efeitos imediatos na mente das pessoas. (BAUMAN, 1999, p.75)

Se voltarmos mais uma vez as propostas de emenda, passamos a entender a causa da existência de tantas PECs. Como vimos foram mais de cinquenta projetos apresentados no Congresso Nacional, e como visto o projeto se apresenta enquanto solução imediata para a problemática vivida naquele determinado momento histórico. Exemplificando, no caso do menino João Hélio, os projetos previam em especial punições mais severas a adultos que utilizassem adolescentes para cometer crimes, exatamente o que havia acontecido. No caso do estudante Victor Hugo Depmann, o adolescente que cometeu o ato, estava prestes a completar dezoito anos, então agora os projetos mudam foco, e falam na possibilidade de punição pelo adolescente depois que ele completar dezoito anos.

Além de tudo isso, encontramos a resposta para o grande número de propostas quase que idênticas, ou seja, ela se deve a necessidade de os políticos terem seus nomes expostos como autores dessas PECs, o que lhes dá ainda mais notoriedade, podendo ainda tudo isso servir de mote de campanha eleitoral. É preciso ter muito cuidado com viés 
populista que a mídia dá a toda notícia com maior capacidade de comoção social, que por vezes está servindo a jogos políticos. (CALLEGARI; WERMUTH, 2013, p.34).

O que seria uma resposta muito plausível para a grande quantidade de proposituras apresentados nos períodos posteriores aos casos emblemáticos aqui discutidos, demonstra também a má qualidade dos projetos, que usam o mesmo argumento todo o tempo, sem problematizar e discutir de forma coerente e cuidadosa, como necessita este tema e qualquer outro de relevância para a sociedade.

\subsection{MÍDIA COMO FATOR DE CRIMINALIZAÇÃO DA VIOLÊNCIA JUVENIL}

Como já dito anteriormente, a mídia é um grande formador da opinião pública. A criminalidade juvenil é tão fortemente explorada pela mídia, que a sociedade tem a sensação de que os adolescentes são grandes inimigos da nossa sociedade.

Os meios de comunicação difundem um inimigo, que precisa ser derrotado, o que deixa toda a sociedade temerosa diante dele, que seria um grande mal. São utilizados alguns instrumentos como o falseamento de dados, o apelo emocional que sensacionaliza a dor das vítimas. (GOMES,2010, p.26). Assim como nos casos de crimes cometidos por adolescentes, dados apresentados anteriormente demonstram que apenas $10 \%$ dos crimes são cometidos por adolescentes, mas a sensação que se tem ao ler uma reportagem ou assistir a um jornal que trata o tema é bem outra, é como se a maioria dos crimes fossem cometidos por adolescentes, e mais, que esses crimes são todos cometidos com grande violência, o que não é verdade. Os crimes cometidos por adolescentes são em sua maioria crimes patrimoniais. Toda essa conjuntura leva os adolescentes cometedores de atos infracionais, a serem vistos como inimigos da sociedade e que, portanto não devem ter resguardados seus direitos e suas garantias legalmente constituídas.

Essa experiência que se vive no nosso país atualmente, se aproxima ao que Günther Jakobs chamou de direito penal do inimigo, que tem por características exatamente o que foi elencado acima. Isso por que, em nossa realidade, quando eleito o adolescente que comete atos infracionais, como inimigo, busca-se reduzir a maioridade penal, ou seja, criminalizar os adolescentes que têm seus atos infracionais regidos pelo ECA, e ante tal medida serão criminalizados pelo direito penal. Pois, diante da mensagem passada pelos meios de comunicação, os adolescentes deixam de ser cidadãos e passam a compor um grupo que pode-se denominar de não-pessoas, pois não conseguem se adequar a ordem de direito vigente. E que segundo Günther Jakobs, deixam de ser pessoas e não 
devem ter as mesmas garantias e direitos precisando ser combatidos, pois eles não podem ter as mesmas prerrogativas de uma pessoa. Tudo isso acontece por que segundo o direito penal do inimigo, estas não-pessoas, não dão garantias de que voltarão a ser fieis ao ordenamento jurídico. (JAKOBS, 2007, p.57 apud CALLEGARI; WERMUTH, 2010, p.62 a 65$)$.

A mídia ao colocar adolescentes na posição de grandes inimigos irrecuperáveis comete grave erro, pois há nos adolescentes uma maior capacidade de recuperação do que em qualquer adulto, o adolescente ainda está em processo de formação. Sendo tal medida, portanto, uma diminuição de direitos e de garantias asseguradas pelo ECA e pela constituição federal, completamente incompatíveis com um estado democrático de direitos e com o princípio da dignidade da pessoa humana.

A grande mídia e setores da sociedade anunciam estas medidas como solução para o problema, já que agora os adolescentes ficarão presos, longe da sociedade, integrando aquele grande exército de reserva que se encontra nas prisões, que não pode viver em sociedade, pois não se adequa a ordem social vigente, não está dentro dos padrões aceitáveis.

Políticas como as que buscam a redução da maioridade, voltadas para a expansão do direito penal, têm por intenção refrear o clamor social por punição àqueles que a sociedade entende serem seus inimigos, são tentativas de solucionar os conflitos existentes dentro da sociedade, refreando as queixas da sociedade. Mas, estas medidas, que não solucionam os problemas, pelo contrário geram novos.

O Poder Legislativo é quem busca satisfazer o clamor social, como nos dizem André Callegari e Maiquel Wermuth: “Os legisladores de plantão estão sempre prontos com seus pacotes de medidas de resolução da criminalidade que se traduzem, normalmente, em aumento de penas e restrições de garantias." (CALLEGARI; WERMUTH, 2010, p.52). Então, diante do discurso midiático, que forma a opinião pública em determinado sentido, coage os políticos a seguirem caminhos idênticos, sob pena de serem hostilizado pelas mídias, pelos próprios políticos e pela sociedade. "Isso porque o político que pretender confrontar o discurso majoritário acerca da criminalidade é logo desqualificado e marginalizado dentro do seu próprio partido, razão pela qual acaba por assumi-lo [...].” (CALLEGARI; WERMUTH, 2010, p.52).

As mudanças legislativas têm por condão satisfazer as insatisfações da sociedade de modo geral. A grande questão é que quando essas aspirações são atendidas, não se faz uma discussão que aprofunde os temas e os discuta com responsabilidade, o 
"legislador, na maioria das vezes, sem intermediários especializados, ou seja, sem interposição de uma reflexão que valore as complexas consequências a que toda decisão penal conduz." (Callegari; Wermuth, 2010, p.54).

A mídia e em especial os programas policialescos, discutem o tema, pregam o completo desrespeito a qualquer direito ou garantia legalmente previstos. Utilizam-se dos casos em que adolescentes cometem atos infracionais até 'espremer a última gota de sangue possível de sair daquele episódio', o que gera nas pessoas sensações das mais variadas, como medo, raiva, sentimento de vingança, além do que mostram os casos somente a partir da ótica da vítima.

Com a maior parte da população é favorável à redução, os políticos, ou pelo menos a maioria deles, também serão, poucos sairão em defesa de soluções menos populares, pois estarão sujeitos sofrer com derrotas eleitorais e serem hostilizados pela população e pelos meios de comunicação.

A desenfreada expansão do direito penal, para acalmar os ânimos da sociedade é uma forma também de diminuir as responsabilidades políticas, pois é muito mais fácil criar leis sem nenhum cuidado e que de imediato terão o resultado pretendido, que não necessariamente seja resolver os problemas enfrentados, mas sim aplacar a efervescência social. Desse modo, as políticas mais indicadas para resolver as questões são desde logo afastadas, pois são em sua maioria de longo prazo e não servem para serem utilizadas pelos políticos em campanhas eleitorais, pois demoram demais a surtir os efeitos pretendidos.

O direito penal passa a ser algo eminentemente simbólico, as leis penais passam a ser simplesmente um símbolo de que o legislativo tem feito algo, tem se movimentado em satisfazer o afã social. Pode-se falar também em um populismo punitivo, como asseveram Callegari e Wermuth (2010, p.56): "Vislumbra-se, assim, o surgimento de um certo 'populismo punitivo' que pode ser definido como aquela situação em que considerações eleitorais primam sobre as considerações de efetividade". Os crimes batem à porta da população e diante do receio de se tornar vítima, as pessoas querem respostas imediatas, o que utilizado é pelos políticos quando usam a soluções rápidas, tentando passar a sensação de tranquilidade à população.

Todo esse complexo sistema cria o que alguns pensadores chamam de direito penal simbólico, que dão uma falsa percepção da realidade, analisam: 
Neste contexto, o direito penal, no afã de dar respostas rápidas às demandas populares, assume cada vez mais um caráter simbólico, dado que proporciona resultados político-eleitorais imediatos a partir da criação, no imaginário popular, da impressão tranquilizadora de um legislador atento e decidido. (CALLEGARI; WERMUTH, 2010, p.56 e 57).

O direito penal simbólico é uma construção jurídica que busca trazer credibilidade para as instituições do estado, pois diante das pressões sofridas pela população o poder legislativo age, mas age de forma irresponsável, pois a lei criada tem simplesmente o condão de se tornar um símbolo para acalmar as insatisfações sociais.

Importante destacar o que assevera Pierre Bourdieu, sobre o poder simbólico. Para ele o poder simbólico é algo que está no campo da magia e que mesmo sendo algo mágico, não palpável é tão forte quanto à força física ou econômica, mas que precisa antes de qualquer coisa ser reconhecido, mesmo que esse poder não seja percebido, sendo algo invisível, mas que compreende a necessidade de cumplicidade das partes que o exercem (BOURDIEU, 1989). Tal complexo conceito, um pouco se diferencia do trazido pelo direito penal simbólico, na medida em que este é muito mais palpável, está muito mais vinculado a realidade, é simbólico no sentido de não trazer resultados práticos positivos, verdadeiros, pois não serve para o fim a que se destina, tem a intenção apenas de gerar nas pessoas sensações determinadas.

O direito penal pode assumir inúmeras facetas e servir para variados fins. Dentro da composição do direito penal do inimigo, discutido no início deste tópico, encontramos o direito penal simbólico, que somado ao direito penal punitivista, acabam por forma-lo. São outros dois fatores que caminham de forma independente, mas que quando se juntam dão origem ao direito penal do inimigo. Como quando observamos o quão drástica, ou seja excessivamente punitivista, é a medida da redução, ao tempo em que sua finalidade principal é esmaecer o clamor social. Além disso, pode-se observar que estes fenômenos vão na contramão dos princípios norteadores do direito penal, como a intervenção mínima, proporcionalidade e humanidade, de forma geral.

A atuação do estado desta maneira é muito perigosa, pois pode trazer resultados muito negativos, pois estes ditos inimigos na maioria das vezes não merecem um tratamento com tamanho rigor, coloca-se em dúvida o princípio da razoabilidade e afasta-se daquilo que se pode chamar de estado democrático de direitos. Mas é preciso entender que direito o penal não é a solução para todo e qualquer problema social, ele deve ser a ultima ratio, sua atuação deve se restringir as situações que não são resolvidas 
por outros ramos do direito, ou até mesmo de outras formas que são estejam diretamente relacionadas ao direito, como políticas sociais.

\section{CONSIDERAÇÕES FINAIS}

Ao analisar os aspectos do tema proposto, conseguimos enxergar à guisa de conclusão algumas nuances que o permeiam. Primeiramente, na observação feita sobre os meios de comunicação foi possível perceber que a mídia exerce um papel de extrema importância na democracia moderna. Ela atua fiscalizando atos dos Estado e também trazendo para a sociedade a narrativa dos fatos sociais, difundindo informações. Porém, ela representa, antes de tudo e paradoxalmente, a força e a vontade de seus detentores e clientes/anunciantes. Logo, há por trás da informação tida objetiva, a criação de outras realidades e verdades, que passam a dominar o senso comum. Assim, desvirtua-se da função que lhe atribuída (ilusoriamente) e constitui-se como um elemento antidemocrático e de risco para a construção do pensamento na sociedade.

Quando a mídia passa a buscar somente a satisfação desses seus interesses ocultos, aumentando seus níveis de audiência, com a criminalização da violência juvenil e da pobreza, por exemplo, ela se torna forte arma na manipulação social. Com isso, atribuem-se aos grupos midiáticos poderes imensuráveis, aptos a enfrentar até mesmo os poderes constitucionalmente constituídos. Nesse sentido, viu-se que os grandes grupos midiáticos, cada vez mais, arvoraram-se na busca por influência, exercendo, pois, a posição de um "Quarto Poder”, para além da tríade legal de poderes brasileiros.

As razões dessa dinâmica midiática localizam-se no apelo de que a mídia seja rentável financeiramente, ou seja, há uma pressão do campo econômico, para que os meios de comunicação gerem lucro. Para satisfazer os interesses econômicos, precisa-se de audiência para manterem-se ativos, nessa marcha capitalista, não se medem esforços. A mídia afasta-se de seu papel visto para muitos como primordial e originário, o concebido ilusoriamente, como informar/fiscalizar, e passa a exercer uma função de invenção de nossas realidades/verdades.

Quanto à análise das propostas de Emenda à Constituição tendentes a reduzir a maioridade penal e as produções midiáticas de períodos anteriores e posteriores a propositura destas, percebeu-se a íntima relação entre tais. Isso porque em quase todas as propostas veiculava-se algum caso de ato infracional cometido por adolescente. Até nos atos cometidos por adolescentes que não geravam uma repercussão nacional, mas 
somente local, deputados ou senadores pertencentes da região da ocorrência apresentaram propostas. Quando a repercussão do crime era nacional, o número de propostas foi ainda maior e feitas por deputados e senadores das mais variadas regiões do país.

Além disso, observou-se são dezenas de propostas com textos idênticos que praticamente não trazem novidades quanto ao tema. Tal situação revela que os projetos têm um cunho muito mais eleitoreiro do que propriamente de buscar uma solução para o problema: cada deputado e senador precisa de um projeto para chamar de seu, aparecendo como bons legisladores que trabalham para satisfazer as necessidades da sociedade, e utilizar-se disso como slogan de campanha frente ao eleitorado - já persuadido pela mídia sobre a necessidade de redução, tendo em vista o falacioso argumente de que a violência juvenil é situação regra no Brasil e não excepcional.

Notou-se que é diante da imensa repercussão dos casos noticiados pela mídia, geradora de comoção na sociedade, que há uma pressão em especial sobre o Poder Legislativo, que se vê coagido a dar alguma resposta imediata à sociedade.

É nessa trilha que se chega a uma produção legislativa referente à redução da maioridade penal meramente simbólica e emergencial, pois ela tem claramente uma intenção que é arrefecer as pressões da população, e não buscar alterar de fato a questão dos adolescentes em conflito com a lei, em situação de vulnerabilidade, tem efeito meramente representativo. Não se discutindo o tema com o cuidado e responsabilidade que ele exige, acarretando consequências desastrosas, como a expansão de um direito penal deslegitimo e disfuncional, porque ineficiente na redução da violência.

$\mathrm{Na}$ última parte do trabalho mostramos a complexidade das questões que estão invisíveis quando se discute simplesmente reduzir ou não a maioridade penal. Quando se discute a redução não se fala que a grande maioria dos jovens que cometem atos infracionais são negros e pobres, portanto, a campanha da redução é mais uma lei penal seletiva porque voltada para um determinado grupo social. Não se rememora quais são os fatores que estão levando a adolescentes cometerem atos infracionais, simplesmente buscam puni-los, ao invés de trazê-los para compor o tecido social, buscase exclui-los do extrato social. Esta problemática é parte do paradigma da segurança cidadã, que pelo estudado, ocorre quando se dá maior importância ao sistema punitivo do que aos problemas sociais.

Em similitude com o direito penal do inimigo, elege-se um ou alguns grupos como inimigos da sociedade e que precisam ser combatidos. Os adolescentes são em muitas oportunidades colocados como grandes inimigos da nossa sociedade e não devem 
ter nenhuma prerrogativa ou garantias constitucionais, não devem ser tratados como seres humanos. É o que vem acontecendo com adolescentes que cometem atos de violência, a sociedade os enxerga como grandes inimigos irrecuperáveis que não devem ser assistidos por nenhum direito, precisam somente ser excluídos da sociedade e utopicamente todos os problemas seriam resolvidos. Por outro lado, é preciso trazer aos questionamentos os problemas sociais que vivemos, da má distribuição de renda, má qualidade de ensino público e em algumas situações a completa ausência do Estado com a implementação de políticas públicas para os jovens.

Ademais, a mídia mostrou-se como precursora do movimento que pede a redução da maioridade penal e da onda de criminalização de adolescentes, levando a população a crer que os grandes vilões da sociedade moderna são eles. Quando a mídia mostra casos de atos cometidos por adolescentes e irresponsavelmente imputa a eles a escalada da violência, isso gera uma grande sensação de insegurança na sociedade, que clama por mais segurança e pede a redução da maioridade. Por isso, que as pesquisas indicam que as pessoas nunca foram tão favoráveis a redução.

Por fim, concluímos haver uma relação inequívoca entre o Poder Legislativo (na criação de leis penais) e a mídia, o Quarto Poder, que formam uma engrenagem complexa e recursiva (interligam-se e se auto alimentam). Portanto, restou claro que o caminho da redução não é o melhor, é preciso em primeiro lugar que se discuta, por exemplo, o desrespeito ao Estatuto da Criança e do Adolescente, que se observe a má qualidade dos espaços onde adolescentes em conflito com a lei cumprem medidas socioeducativas. Por mais que algumas vezes adolescentes cometam atos bárbaros, que não representam mais que $10 \%$ das condutas cometidas no país, não se justifica reduzir a maioridade penal, levando em consideração aquele caso isoladamente noticiado amiúde

pelos meios de comunicação. É preciso uma visão holística do fenômeno para além do medo sensacionalista e lucrativo veiculado midiaticamente.

\title{
REDUCTION OF CRIMINAL AGE AND MEDIA: A CRITICAL ANALYSIS ON VIOLENCE JUVENILE CRIMINALIZATION
}

\author{
Ana Clara Montenegro Fonseca
}

Mateus Carvalho Sá 


\begin{abstract}
This paper focuses on the issue of reducing the penal age and their relationship with the media field productions that influence the criminalization of youth violence of speech, providing, in particular, the construction of a purely symbolic criminal law, from productions emerging legislation. It starts with an unusual perspective on the subject of the treatment, because the purpose proposed herein distance from the debate located the difference between positions in ideological movements to be for or against the reduction. In this sense, approaching the investigation of new arrangements that promote changes in social relations, highlighting the effects of media power, considered a fourth power, which runs between the people and influences the appearance of new truths, such as "reducing solution is "for example, and from that, we see the effectiveness (or not) that criminal law has to answer such questions. To this end, it emphasizes the theoretical nature of the research, with critical and interdisciplinary position, in order to explain the relationship between the phenomenon (reduction of majority) and other contexts (law, media and politics). The article is structured by presenting the concept adopted in the media study as a fourth power, then focuses the discussion on the economic, sensationalism and fear culture as media service the instruments and, finally, deals with the role that media the formation processes of criminalization of youth violence that impact on creation of legislative proposals on the subject in contemporary times. Thus, we see the existence of a complex mechanism that brings together the media, legislative production and the reduction of criminal responsibility, which the legalistic debate alone is insufficient in the apprehension of its meaning, so the transdisciplinary approach proposed points new horizon in order to enrich the discussion.
\end{abstract}

Keywords: Media. Reduction of criminal age. Criminalization. Violence. Legislative

\title{
REFERÊNCIAS
}

BAUMAN, Zygmunt. Globalização: as consequências humanas. Trad. Macus Penchel. Rio de Janeiro: Jorge Zahar, 1999.

BOURDIEU, Pierre. O Poder Simbólico. Trad. Fernando Tomaz. Rio de Janeiro: Bertrand Brasil S.A., 1989.

BOURDIEU, Pierre. Sobre a Televisão. Rio de Janeiro: Jorge Zahar ed, 1997.

CALLEGARI, André Luís. WERMUTH, Maiquel Ângelo Dezordi. Sistema penal e política criminal. Porto Alegre: Livraria do Advogado,2010.

CALLEGARI, André Luís. WEBBER, Suelen. Os Ruídos e as comunicações estabelecidas entre direito penal, sistema político e os meios de comunicação: o surgimento de um discurso expansionista. Revista da AJURIS- v.40- n.129, p.37-62, março,2013. 
CALLEGARI, André Luís; WERMUTH, Maiquel Ângelo Dezordi. "Deu no Jornal”: notas sobre a contribuição da mídia para a (ir)racionalidade da produção legislativa no bojo do processo de expansão do Direito Penal. Revista Liberdades, n.02, p. 56-77, setdez, 2009.

DUARTE, Solange. Para os jovens, a lei da impunidade. O Globo, São Paulo, p.8, 29 de set de 91. Disponível em: www.acervo.oglobo.globo.com. Acesso em: 26 de abr de 2015.

FOUCAULT, Michel. Vigiar e Punir: História da violência nas prisões. Petropolis: Vozes, 2010.

GLASSNER, Barry. Cultura do Medo. Trad. Laura Knapp. São Paulo: Francis, 2003.

MASCARENHAS, Oacir Silva. A influência da mídia na produção legislativa penal brasileira. In: Âmbito Jurídico, Rio Grande, XIII, n. 83, dez 2010. Disponível em: $<$ http://www.ambitojuridico.com.br/site/?n_link=revista_artigos_leitura\&artigo_id=872 $7 \&$ revista_caderno $=3>$. Acesso em mai 2015 .

OLIVEIRA JUNIOR, Paulo Eduardo Duarte de. Processo penal e mídia: a cultura do medo e a espetacularização dos juízos criminais. São Paulo 2012. Disponível em: http://biblioteca.asav.org.br/vinculos/000006/00000694.pdf. Acesso em: 28 de mai 2015.

Presidência da República. Secretaria de direitos humanos. Adolescente em conflito com a lei: guia de referência para a cobertura jornalística. Brasília, DF: ANDI/ comunicação e direitos, 2012. 